\title{
The relationship between demographic variables and well-being of women in South African workplaces
}

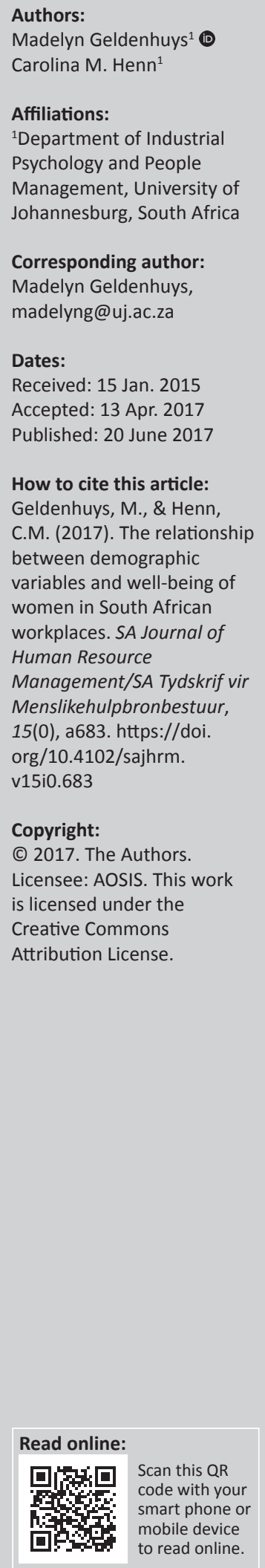

Orientation: It is important to investigate the determinants of well-being among working women. Given the unique demographic diversity within the South African context, differences in the experience of well-being among women are expected.

Purpose: The study investigated the effects of age, race, marital status and educational status on psychological meaningfulness, life satisfaction, work-family conflict and social support of working women.

Motivation: With the increase of women in the workplace, there is a need for knowledge and understanding of the factors that influence the well-being of women. This study aims to investigate demographic variables as determinants of well-being among working women.

Method: Cross-sectional surveys were used to gather data from a sample $(n=540)$ of women from various South African companies. The Utrecht Work Engagement Scale (UWES), the Psychological Meaningfulness Scale (PMS), the Satisfaction with Life Scale (SWLS), the WorkRole Conflict Scale and the Job Demands Resources Scale (JDRS) were administered.

Results: Significant relationships were found between life satisfaction, work-to-family conflict and work engagement, respectively, and marital status. Higher levels of education showed significant relationships with life satisfaction and work-to-family conflict. Being white showed significant positive relationships with life satisfaction, work-to-family conflict and work engagement. With regard to social support and psychological meaningfulness, race explained significant amounts of variance in psychological meaningfulness, as did age.

Practical, managerial and methodological implications: The findings indicate that the experiences of well-being among women vary by age, race, marital status and educational status. It is therefore imperative that human resource practitioners appropriately measure these differences, accommodate them in policies through relevant supportive practices and also champion these practices for women.

\section{Introduction}

The nature of work and society has changed in such a way that increasing numbers of women enter the workplace. Owing to factors such as organisational and societal architecture, career progression for men and women are different (Fagenson-Eland \& Baugh, 2000; O'Neil, Hopkins \& Balimoria, 2008). Compared to men, women often fulfil more work roles, which results in them spending time doing both formal and informal work. More specifically, they are employed by organisations on a full-time basis, which constitutes paid work, yet they also do more unpaid work than men do (Organisation for Economic Co-operation and Development [OECD], 2011). Unpaid work in the context of this study refers to household - and family tasks such as childrearing and domestic chores. Indeed, although men are assuming greater responsibility for family and household duties, women continue to do most of this work (Douglas \& Michaels, 2004; Greenhaus \& Parasuraman, 1999). This also holds true in the South African context (Mostert, 2008). Owing to these types of gendered social contexts ( $\mathrm{O}^{\prime} \mathrm{Neil}$ et al., 2008), it seems prudent to follow womenspecific research approaches more often.

It is often the case that women do not properly recover from work stress (cf. Sonnentag, 2003) or struggle to balance multiple roles, resulting in work-family conflict as a negative consequence (Opie \& Henn, 2013; Rathi \& Barath, 2013). This can, in turn, affect their well-being, which can manifest in different ways. Well-being is described as a reaction to events in life that informs satisfaction, happiness and fulfilment in the personal and work lives of people (Diener, Oishi \& Lucas, 2003). Experiencing well-being at work involves work engagement (Rothmann \& Rothmann, 2010), meaningfulness at work (Van Zyl, Deacon \& Rothmann, 2012) and life satisfaction 
(Williamson \& Geldenhuys, 2014). Well-being is further affected by the demands and resources placed on people by work (Demerouti, Bakker, Nachreiner \& Schaufeli, 2000).

Differences exist in terms of how people experience wellbeing (Diener, et al., 2003). In this regard, demographic differences can also be expected to affect how women approach work, how they engage at work, how they find meaning, how they use resources, how they respond to work-family conflict and how satisfied they are. As noted by Addai, Opoku-Agyeman and Amanfu (2014) as well as Ngoo, Tey and Tan (2015), more research on how people experience well-being has been conducted in developed countries than in African contexts. Most of the studies in the developed contexts either investigated the main effects of demographic variables such as age, race and educational status, or controlled for them (cf. Addai et al., 2014; Ngoo et al., 2015).

Organisations are giving increasing attention to the fostering of well-being at work (Addai et al., 2014; Van Zyl et al., 2012). However, it becomes more difficult to help employees cope with work as demands at work and home become more complex. The situation is further complicated by personal differences. Specifically, it may benefit organisations, managers and employees if differences based on demographics are acknowledged and understood. This will enhance our understanding of the demographic determinants of work engagement, psychological meaningfulness, life satisfaction, work-family conflict and social support among women in the South African workplace. Holvino (2010) states that:

\footnotetext{
... 'women' is not a universal experience or category; we must identify, untangle and suggest interventions to change the differential impact that everyday practices have for different women in different types of organizations. (p. 264)
}

Organisations, employees and managers can benefit from this knowledge because they would be able to understand that women function, cope and experience work differently and acknowledge that women would be better able to invest themselves in the organisation when receiving appropriate support. Although perhaps it may seem logical that this is understood in organisations, it is in fact not yet fully the case. For example, as pointed out by Bosch (2016), managers often consider female employees to be wonderful, until the moment they fall pregnant. At that point pregnancy in female employees becomes a 'hassle factor' (Bosch, 2016, p. 5). In this example, therefore, it is evident that age (relating to life cycle factors such as childbearing ability and age of children) and income (relating to educational status and ability to afford childcare) become salient demographics that must be considered.

\section{Purpose}

Demographic variables are often important determinants of well-being (Addai et al., 2014; Ngoo et al., 2015). There is plentiful literature supporting the notion that demographic variables impact organisations in numerous ways. To name but a few, Mandu, Buitendach, Kanengoni and Bobat (2004) showed that demographics such as age, race and educational status influence turnover intention; Balogun (2014) found that demographic variables impact employees' willingness to share knowledge; and Dwivedi, Kaushik and Luxmi (2015) proved that age, educational status and marital status influenced organisational citizenship behaviour. Therefore, this study aimed to provide information regarding the relationship between race, age, marital status and education on the one hand, and work engagement, psychological meaningfulness, life satisfaction, work-family conflict and social support on the other hand. Not only did the study aim to establish whether there are significant relationships between the demographic variables and well-being constructs, but it also measured the amount of variance in these well-being constructs that are explained by race, age, marital status and education. An understanding of how women appraise their own life circumstances and their subjective well-being will inform workplace policies and managerial principles in such a way that women will benefit from these (cf. Addai et al., 2014). This study provides crucial information regarding the impact of demographic factors on women's well-being in the workplace. A true understanding of women in the workplace is certainly not limited to demographic factors only. Nonetheless, demographic variables are an important piece of the puzzle, so to speak. It can inform policies and managerial principles, for example in the development of wellness programmes suited to female employees, policies relating to maternity leave and other women-related health issues and policies regarding flexitime. As indicated by Nienaber, Bussin and Henn (2011), in terms of reward preferences it is impossible for organisations to take into account all aspects that influence well-being on an individual employee level. Therefore, segmentation of employees into groups with similar characteristics and needs may be an effective strategy (cf. Nienaber et al., 2011). An understanding of demographic factors can enable employers to apply such segmentation to enhance employee well-being and subsequently also overall organisational effectiveness.

\section{Work engagement}

The construct of work engagement as a desirable occupational health outcome has received increased research attention in recent years (cf. Bakker, Schaufeli, Leiter \& Taris, 2008; Mills, Culbertson \& Fullager, 2011). Work engagement is defined as 'a positive, fulfilling, work-related state of mind that is characterized by vigour, dedication and absorption' (Schaufeli, Salanova, González-Romá \& Bakker, 2002, p. 74). Vigour is described as high energy levels while working, eagerness to devote energy to one's work, resilience and tenacity even when faced with challenges. Dedication indicates almost complete involvement in one's work and the experience of meaning, challenge, pride, zeal, motivation and stimulation. And finally, absorption refers to being completely submerged in and focused on one's work to such an extent that one loses track of time and finds it difficult to withdraw from work (Bakker et al., 2008). There is international research available regarding the relationship between the demographic variables of interest in this study and work engagement, but little within the South African 
context (Bezuidenhout \& Cilliers, 2011; Durksen \& Klassen, 2012; Fong \& Ng, 2012; Haley, Mostert \& Els, 2013).

With regard to age, Fong and $\mathrm{Ng}$ (2012) found significantly higher scores on all three dimensions of work engagement among older Chinese employees. Likewise, Mahboubi et al. (2014) also found higher work engagement levels among older participants. In South African literature, Bezuidenhout and Cilliers (2011) found a significant positive correlation between vigour and absorption on the one hand, and age on the other hand, in a South African sample. Also in a South African sample, older participants reported significantly higher scores on dedication (Haley et al., 2013). It is possible that age acts as a proxy for life stage in terms of its effect on work engagement. More specifically, older employees are more likely to have grown independent children, which enables them to focus more exclusively on their jobs.

Bell and Barkhuizen (2011) reported significant correlations between work engagement and ethnicity in a South African sample. More specifically, white participants scored significantly higher across all three dimensions of work engagement than coloured participants. White participants also scored significantly higher than black participants in terms of absorption. Takawira (2012), however, found no effect for race on work engagement, also in a South African sample.

In terms of education, the literature does not present hardand-fast findings. Mahboubi et al. (2014) found no significant relationships between work engagement and level of education. In a South African sample, participants with a matric qualification reported significantly higher absorption levels than participants with a doctoral degree (Bell \& Barkhuizen, 2011). Barkhuizen and Rothmann (2006) reported almost the exact opposite in a group of South African academics; those with doctoral degrees had significantly higher levels of absorption than those with Honours degrees or equivalent 4-year degrees.

The results relating to work engagement and marital status are indeterminate. Kong (2009) reported significantly higher levels of vigour, absorption and dedication among unmarried employees compared to married ones. Takawira (2012) found higher levels of vigour among married people than among single people. No differences were observed in terms of marital status and either absorption or dedication.

\section{Psychological meaningfulness}

In the work context, meaningfulness can manifest in terms of psychological meaningfulness (Geldenhuys, Łaba \& Venter, 2014). Meaning is defined as the value of certain work goals in relation to personal views, morals and standards (Geldenhuys et al., 2014; May, Gilson \& Harter, 2004; Olivier \& Rothmann, 2007). Furthermore, Kahn (1990) defines workrelated meaningfulness as '... a feeling that one is receiving a return on investment of one's self in a currency of physical, cognitive and emotional energy' (Kahn, 1990, pp. 703-704).
Meaningfulness in life affects the psychological well-being of people (Frankl, 1997). Meaningful work makes an important contribution to optimal experiences in the workplace (cf. Lips-Wiersma \& Wright, 2012). Meaningful work has also been related to work engagement (Van Zyl et al., 2012), life satisfaction (Williamson \& Geldenhuys, 2014) and motivation (Chalofsky \& Krishna, 2009).

According to Seligman (2002), meaning helps people transcend as well as find a purpose in life (Steger, Oishi \& Kashdan, 2009). However, according to Csikszentmihalyi (1990), the construct 'meaning' is difficult to capture and is referred to as the significance something holds for a person. Noting that meaningful work can manifest differently, firstly as a fulfilment - where people pursue their passion - and secondly the view of what people contribute to an aspect that is larger than life (Wolf, 2012).

From a gendered approach, it would appear that there are differences in terms of meaningfulness and work engagement based on gender. Women tend to experience a weaker relationship between these constructs (Williamson \& Geldenhuys, 2014). Generally, the demographics of people were found to have a minimal effect on meaning at work (Hodson, 2002). No differences were found based on race and gender respectively and meaningful work (Hodson, 2002). No evidence in the literature could be found to explain any difference based on education. Pertaining to age, no conclusive differences could be found in terms of psychological meaningfulness. However, Chalofsky and Krishna (2009) point out that nearing retirement age, people start questioning the meaning in their work.

\section{Life satisfaction}

Life satisfaction is a well-known subjective well-being construct (cf. Henn, 2013). It is defined as a 'cognitive, judgemental process' (Diener, Emmons, Larsen \& Griffin, 1985, p. 71). Life satisfaction is seen as the way in which individuals evaluate the quality of their lives from a global and cognitive perspective (McDowell, 2010). It further refers to the judgement of the levels of happiness when a person realises their levels of success (Pavot \& Diener, 1993). Thus a person subjectively appraises his or her life by comparing it to an internally derived standard. Literature reveals a number of studies that have found relationships between the selected demographics variables of interest in the current study and life satisfaction.

Fagley (2012), Filiz (2014) and Ngoo et al. (2015) found no significant relationship between age and life satisfaction. Liang and Liu (2014) reported a positive correlation between age and life satisfaction. Schafer, Mustillo and Ferraro (2013) established that as age increased, partner satisfaction became an increasingly important determinant of life satisfaction for females. Botha and Booysen (2012) found a U-shaped relationship between age and life satisfaction. In their overall South African sample, life satisfaction decreased until the age of 36 , after which it started to increase again. 
Researchers have examined the relationship between ethnicity and life satisfaction. Life satisfaction varied significantly across different Ghanaian ethnic groups (Addai et al., 2014). Davis and Wu (2014) reported that among white Americans, individual life satisfaction decreased when group income increased, whereas among blacks, individual life satisfaction increased with increased group income. This is an interesting finding, indicating that individuals compare themselves with their social group in measuring their life satisfaction. Black people are generally considered to have a collectivistic culture, and an increase in group income is in a sense 'shared' among the group. White people on the other hand are generally considered to have individualistic cultures, and therefore an increase in group income may be perceived as negative by an individual who does not share in that increase (cf. Triandis's 1989 review of the literature in this regard). It should be borne in mind, though, that better education can lead to less collectivism, and one can therefore not merely ascribe these differences to collectivism or individualism. As Oyserman (1993, p. 1006) points out, at university 'an individualistic perspective is likely to be prompted by academic achievement demands that focus on individual striving, competition and actualization of potential'. Furthermore, better education is linked to higher income (i.e. wealth), which is a precursor of individualism (Triandis, 1989).

Davis and Wu (2014, p. 867) state that 'an individual's racial and ethnic identity matters in determining the reference group with which he or she engages in social comparison'. This can, in turn, influence the individual's judgements of subjective well-being. Fagley (2012) did not find any significant relationships between ethnicity and life satisfaction in an American sample. In a South African study, white, coloured and Indian people were significantly more satisfied with life than black people (Botha \& Booysen, 2012).

With regard to the impact of education and wealth on life satisfaction, literature reveals varied findings. Daraei and Mohajery (2013) investigated the life satisfaction of female domestic workers in India. Their findings showed that educational level (as well as income and occupation) was positively related to life satisfaction. Addai et al. (2014) also found a higher probability of life satisfaction in upper- and middle-class Ghanaians than in the lower class. In the USA as well as in Great Britain, lower wealth was significantly associated with lower life satisfaction (Jivray \& Nazroo, 2014). These findings all seem to point in the direction of a relationship between education and income. Education is indeed a gateway to better job opportunities and higher income occupations (cf. Schimmel, 2009), and therefore it seems likely that it will play a role in the relationships between income and occupation on the one hand, and life satisfaction on the other hand. In the USA, lower levels of education were also associated with lower life satisfaction (Jivray \& Nazroo, 2014). In other research, a high school education was associated with higher life satisfaction than those of graduates, and a post-graduate qualification was associated with higher life satisfaction than a lower than high school education (Mahboubi et al., 2014). This shows a curvilinear relationship between education and life satisfaction. Ngoo et al. (2015) reported different findings for different areas in Asia. In South Asia, higher education was significantly related to higher levels of life satisfaction; in Central and West Asia no such relationship was found; and in Southeast Asia the effect was small. However, higher income did have a significant positive impact on life satisfaction in Central and West Asia. This may be because of an indirect influence of education on life satisfaction. Nonetheless, Salinas-Jimenez, Artes and Salinas-Jimenez (2011) found that education had a significant positive correlation with life satisfaction regardless of income. In a South African sample, life satisfaction was significantly positively correlated with income (Botha \& Booysen, 2012), which may also be related to educational qualification.

Several studies have investigated the influence of marital status on life satisfaction, and the evidence is overwhelmingly in favour of a positive relationship between being married and higher life satisfaction. Stack and Eshleman (1998) investigated happiness, financial satisfaction and health (all three of which are closely related to life satisfaction) across 17 nations. Their results showed a significant positive relationship between marriage or co-habitation and the three well-being measures. Ngoo et al. (2015), Lee and Lee (2013) and Filiz (2014) likewise found a significant positive relationship between marital status and life satisfaction. Liang and Liu (2014) reported lower levels of life satisfaction among divorced and widowed participants than among married participants. In a similar way, Botha and Booysen (2012) found significantly higher levels of life satisfaction among married women than any other groups (including married men) in their study.

\section{Work-family conflict}

A widely used definition of work-family conflict that was developed by Greenhaus and Beutell (1985) is that it is:

a form of inter-role conflict, in which the demands of work and family roles are incompatible in some respect, so that participation in one role is more difficult because of participation in another role. (p. 77)

With women increasingly joining the formal workforce (Boushey, 2008; Casale, 2004), it stands to reason that they will be faced with the challenge of balancing the demands of work with those of their family life. Work-family conflict is bi-directional, being work-to-family conflict and familyto-work conflict (Greenhaus \& Beutell, 1985). In addition, different types of work-family conflict have also been identified, namely time-, behaviour- and strain-based (Voydanoff, 2004). Alternative terms have been utilised to describe the inter-role conflict between work and family responsibilities, of which the most common among these are probably work-interfering-with-family and family-interfering-with-work (WIF and FIW) (Noor, 2003). 
In our study, the focus was on work-to-family conflict as research has shown that work-to-family conflict (also called work-family conflict) is of greater concern than family-towork conflict (cf. Bellavia \& Frone, 2005; Greenhaus \& Parasuraman, 1999). In this regard, De Klerk, Nel and Koekemoer (2012) have indicated that it is essential that more South African studies be conducted on work-home interaction, a construct similar to work-to-family conflict. However, to provide a clear context with regard to workfamily conflict in our study, we have included research findings regarding family-to-work conflict.

Work-family conflict has been linked to age in a number of studies. Older individuals correlated significantly with a decrease in work-family conflict in a sample of Spanish working men and women (Gaspar, 2013). Lambert, Hogan, Kelley, Kim and Garland (2013) reported similar results between age and family-to-work conflict. They also found a negative correlation between behaviour and time-based work-to-family conflict and age. Huffman, Culbertson, Henning and Goh (2013) reported a curvilinear relationship between work-family conflict and age, with young and old participants showing the lowest levels of work-family conflict. This finding suggests that life cycle stages also impact on work-family conflict. Allen and Finkelstein (2014) found a negative correlation between age, and WIF and FIW, respectively. More specifically, they reported a negative relationship between age and WIF only within the empty nest stage of the family life cycle. Erickson, Martinengo, and Hill (2010) reported a similar finding. Although both family life cycle and age had significant relationships with workfamily conflict in their study, Allen and Finkelstein (2014) pointed out that the patterns that emerged for family life cycle and work-family conflict were different from those that emerged for age and work-family conflict. It is therefore evident that age and family life cycle relate independently to work-family conflict. Several studies have found no significant relationships between age and work-family conflict, including two South African studies (Gaspar, 2013; Noor, 2003; Pieterse \& Mostert, 2005; Steyl \& Koekemoer, 2011).

Childers and Sage (2004) found that white women were 2.4 times more likely than Asian-American, black and Hispanic women to experience family-to-work conflict. Conversely, Asian-American, black and Hispanic women were 1.4 times more likely than white women to experience work-to-family conflict. It seems that the context of the women impacted on the findings and should be taken into consideration when observing racial differences in levels of work-family conflict. For example, white women in the Childers and Sage study were mostly in dual-earner families, whereas the majority of Asian-American, black and Hispanic women were the only earners in their families. Also, white women were in positions that indicated higher education and training, whereas AsianAmerican, black and Hispanic women were much more likely to be employed in lower-paying jobs performing manual work.
Childers and Sage (2004) found education to be the strongest predictor of family-to-work conflict among white women. Gaspar (2013) found that education had a significant impact on work-family conflict in a British sample, with higher education predicting higher levels of work-family conflict. Noor (2003) reported a similar finding, with a significant positive correlation between level of education and FIW, as did Ozutku and Altindis (2013), who found higher behaviourbased work-to-family conflict for health care professionals with doctoral degrees. Schieman and Glavin (2011) reported a curvilinear relationship between education and workfamily conflict. Participants with higher (post school) and lower (less than high school) levels of education reported more work-family conflict than those with a high school education. The authors theorised that those with higher levels of education may experience 'stress of higher status' owing to the positions they occupy, with increased difficulty in balancing the demands of work and family (Schieman \& Glavin, 2011, p. 1342). Higher work-family conflict levels among participants with lower levels of education may be attributed to factors such as lower incomes and the nature of lower income occupations (e.g. shift work).

With regard to marital status, the literature shows mixed results. Eagle, Icenogle, Maes and Miles (1998) found that divorced women experienced the highest time-based familyto-work conflict. Nomaguchi (2011) reported higher hometo-job conflict (similar to family-to-work conflict) for single mothers than for either single fathers or for married people. Steyl and Koekemoer (2011) similarly reported higher private-work conflict for single participants than for married participants. Ozutku and Altindis (2013), Noor (2003) and Mazerolle, Bruening and Casa (2008) did not find any significant relationships between marital status and workfamily conflict.

\section{Supervisor and social support}

Organisational support, as an umbrella term for supervisor and social support, is defined as the extent to which an employee's effort is believed to be valued by the organisation and whether the well-being of employees is cared for (Rhoades \& Eisenberger, 2002). Support is considered a job resource that can fulfil either an intrinsic or an extrinsic motivational role (De Lange, De Witte \& Notelaers, 2008). Intrinsic motivation includes aspects such as personal growth and development, while extrinsic motivation refers to aspects such as the achievement of goals. Social support relates to the individual's belief that he or she is loved, valued and that colleagues are looking out for his or her well-being (Kossek, Pichler, Bodner \& Hammer, 2011). Organisational support theory points out the positive effects of support on well-being at work (Aselage \& Eisenberger, 2003; Shanock \& Eisenberger, 2006). Through social exchange that takes place between people, the perceived organisational support encourages levels of dedication from employees which lead to increased performance. Based on this norm of reciprocity, employees welcome support in the form of tangible rewards (e.g. pay, benefits) and socio-emotional 
rewards (e.g. esteem, approval, caring) (cf. Rhoades \& Eisenberger, 2002; Shanock \& Eisengerger, 2006).

In the workplace, support is an important job resource that tends to increase the levels of well-being of employees (Demerouti et al., 2000). Because employees need to be able to actively engage at work, fulfil job expectations and deal with complex careers (Barkhuizen \& Rothmann, 2006), support becomes beneficial for subjective well-being (Cusack \& Numer, 2012). Social support can enhance positive work outcomes, such as work engagement (De Lange et al., 2008). Supervisor support refers to the extrinsic support offered by a manager to an employee (Shanock \& Eisenberger, 2006). It includes the extent to which the manager acknowledges and allows for the demands placed on employees both at work and privately (Thomas \& Ganster, 1995). Further, supervisor support also includes emotional and practical support, which contributes to employee well-being and work effectiveness (Kossek et al., 2011).

Few studies report on the relationship between demographic variables and organisational support. In a study on the distribution of social support and social ties among white and black employees in America, it appears that racial diversity at work can impact how social ties are formed (Sloan, Evenson-Newhouse \& Thompson, 2013).

In terms of age, Alcover (2012) reported that where older employees experienced breaches in their psychological contract, organisational support mitigated the negative impact thereof. Further, in a sample consisting of married employees, it was found that the interactive term of tenure and organisational support does not reduce work-family conflict (Karatepe, 2009).

It is evident from the literature that results pertaining to demographic differences are not conclusive, yet there is sufficient evidence that demographics do influence wellbeing. Given the diverse nature of the South African workplace, it is expected that the relationships between demographic variables and well-being variables will differ significantly among women. More specifically, this study therefore hypothesises that women will experience workrelated well-being differently based on age, race, marital status, education and language.

\section{Research design \\ Research approach}

To meet the objectives of the study, a cross-sectional survey design was utilised. Data were thus gathered at a particular point in time (Wegner, 2007). The study employed a quantitative approach. Online surveys were utilised to gather the data. Women across various organisations and occupations in Gauteng, South Africa, participated in the study. The online survey was accompanied by a letter explaining the purpose of the study as well as ensuring the participants of both confidentiality and anonymity.

\section{Research method \\ Research participants}

The targeted population consisted of 800 working women. The sample consisted of $n=540$ women and resulted in a $67.5 \%$ response rate. Non-probability sampling was utilised. Organisations (e.g. media, schools, investment companies) were targeted, based on convenience, in order to obtain a diverse sample of women who have worked for one year or more. The sample was further well represented in terms of language, age, marital status and education. As regards race, $50.2 \%$ were white, $25.2 \%$ were black, $16.2 \%$ were coloured and $7.3 \%$ were Indian. Half the women were unmarried $(50.9 \%)$, while the other half were married (49.1\%). Almost 27\% (26.9\%) of the women spoke Afrikaans, $48.7 \%$ of the women were English-speaking and $22.8 \%$ spoke an African language. In terms of age groups, $47.9 \%$ were between the ages of 18 and 34 years, while $48.1 \%$ were between the ages of 35 and 65 years. Pertaining to levels of education, the women were split into two groups: those with a secondary education (54.3\%) and those with a university qualification (43.5\%).

\section{Research procedure}

This study formed part of a larger project. An invitation to participate in the study was sent out by email communication. Participants and organisations voluntarily agreed to complete the survey. An online survey was emailed to participants. A web-link containing the online survey was used, to be accessed via the web, which meant that participants had to have internet access. A cover letter explaining the purpose and significance of the study accompanied the web-link. Further, the confidentiality of the research was explained and guaranteed.

\section{Measuring instruments}

The measuring instruments consisted of a biographical questionnaire, the Utrecht Work Engagement Scale (UWES), the Job Demands Resources Scale (JDRS), the Psychological Meaningfulness Scale (PMS), the Satisfaction with Life Scale (SWLS) and the Work-to-Family Conflict Scale. All the questionnaires are in the open domain. Previous research used the UWES (De Bruin \& Henn, 2013), the JDRS (Jackson \& Rothmann, 2005), the PMS (Geldenhuys et al., 2014), the SWLS (Williamson \& Geldenhuys, 2014) and the Work-toFamily Conflict Scale (Opie \& Henn, 2013).

The biographical questionnaire consisted of questions regarding race, age, language, education and marital status.

The PMS (Spreitzer, 1995), utilised to measure psychological meaningfulness, contains six items that are answered on a 5-point Likert scale ranging from 1 (totally agree) to 5 (totally disagree). The scale measures the degree of meaning that individuals find in work-related activities. A sample item is My job activities are significant to me. Satisfactory Cronbach's alpha was reported in previous studies. May et al. (2004) reported a reliability coefficient of 0.90 . In a 
South African study, Olivier and Rothmann (2007) reported a Cronbach's alpha coefficient of 0.92 . The Cronbach's alpha for this study was 0.95 .

The JDRS was used to measure social support and supervisor support (Jackson \& Rothmann, 2005). The 20 items in this scale are rated on a 4-point scale, ranging from 1 (never) to 4 (always). Social support measures the level of support that is provided by colleagues (I have support from my colleagues at work), while supervisor support measured the support provided by the manager to the direct subordinate (I feel that my manager appreciates my work). Sufficient reliability scores were found with Cronbach's alpha coefficients of 0.8 for organisational support and 0.76 for social support (Jackson \& Rothmann, 2005). This study found a sufficient Cronbach's alpha coefficient of $\alpha=0.95$ for both organisational and social support.

The SWLS is a widely used measure of life satisfaction (Diener et al. 1985). The five-item scale uses a 7-point Likert rating scale that ranges from $1=$ strongly disagree to $7=$ strongly agree. Sample items include I am satisfied with my life and If I could live my life over I would change almost nothing. Braghin (2009) reported a Cronbach's alpha coefficient of 0.91 for this scale. This study found an internal consistency coefficient of 0.88 .

The 9-item UWES (UWES-9 item) was utilised to measure work engagement (Schaufeli \& Bakker, 2004). The items are scored on a 7-point Likert-type scale ranging from 0 (never) to 6 (always). The scale measures the three factors of work engagement, namely vigour, dedication and absorption. A sample item for vigour is When I get up in the morning I feel like going to work. A sample item for dedication is My job inspires me and a sample item for absorption is Time flies when I'm working. As recommended by De Bruin and Henn (2013), the total score was utilised in the analysis. In a South African study, Opie and Henn (2013) reported an alpha coefficient of 0.93 for the UWES-9. The reliability for the UWES in this study was also $\alpha=0.93$.

The Work-to-Family Conflict Scale (Netemeyer, Boles \& McMurrian, 1996) measures work-to-family conflict. It comprises five items that require responses on a 5-point Likert-type scale. Responses range from strongly agree to strongly disagree. Sample items are The demands of my work interfere with my home and family life and My job produces strain that makes it difficult to fulfil family duties. A South African study among working women found a Cronbach's alpha coefficient of 0.92 (Braghin, 2009). This study found a Cronbach's alpha of $\alpha=0.97$.

\section{Statistical analysis}

The statistical analysis was carried out by using SPSS (SPSS Inc., 2013). Data were screened for outliers, typing errors and inconsistencies. Descriptive statistics including means, standard deviation, skewness, kurtosis and reliability were analysed.
Product moment correlation coefficients were determined. In terms of effect sizes, Cohen (1992) provides the following guidelines to practical and statistical significance: $r=0.10$ is indicative of a small effect, $r=0.30$ is indicative of a medium effect and $r=0.50$ is indicative of a large effect. This will indicate the practical significance of the correlations between the variables. A correlation is only practically significant if it is statistically significant (Cohen, 1992).

Owing to unequal sample sizes, relationship status was lapsed into two categories, namely married and unmarried. Similarly, age was split into an '18-34 years' group and a '35-65 years' group. Education was split into 'up to secondary education' and 'some form of tertiary education' groups. Independent samples $t$-tests were performed to compare the mean score differences of the well-being factors based on the demographic factors. For the $t$-test for race, the coloured and Indian groups were omitted from the analysis because these two categories were too small for meaningful analysis. The Levene's test for significance was used to determine whether equal variance based on the demographic factors are assumed (Pallant, 2011). Further, Cohen's $d$ was also investigated as an addition to the $t$-test result in inferential statistics (Cohen, 1992). Cohen's $d$ presents the distance between the two groups being compared based on the standard deviation score. Cohen (1992) suggests that a value of 0.1 is a small effect, 0.3 is a medium effect and 0.5 is large effect. Hierarchical multiple regression analysis was used to determine the amount of variance explained in work engagement, psychological meaningfulness, life satisfaction, work-family conflict and support by age, race, education and marital status. Data were inspected to ensure that the assumptions of normality, linearity and homoscedasticity were met. Multicollinearity values (tolerance and Variance Inflation Factor [VIF]) were within recommended limits (Pallant, 2011).

\section{Results \\ Descriptive statistics}

The descriptive statistics for the well-being constructs are reported in Table 1 . The descriptive statistics include mean scores, standard deviations, skewness and kurtosis.

Table 1 shows the mean scores and standard deviations of work engagement, psychological meaningfulness, workfamily conflict, life satisfaction social support and supervisor support. In terms of skewness and kurtosis, the results

TABLE 1: Descriptive statistics for work engagement, psychological meaningfulness, work-family conflict, life satisfaction, social support and supervisor support.

\begin{tabular}{lcccc}
\hline Item & Mean & SD & Skewness & Kurtosis \\
\hline Work engagement & 37.44 & 10.92 & -0.76 & 0.34 \\
Psychological meaningfulness & 24.06 & 4.89 & -1.09 & 1.80 \\
Work-family conflict & 13.10 & 5.35 & 0.28 & 0.11 \\
Life satisfaction & 23.45 & 6.65 & -0.62 & 0.25 \\
Social support & 40.45 & 8.48 & -0.60 & 0.41 \\
Supervisor support & 33.96 & 11.43 & -0.44 & -0.77 \\
\hline
\end{tabular}

SD, standard deviation. 
indicate that the data were normally distributed and had a normal peak.

\section{Correlations coefficients}

Pearson product moment correlations coefficients for the well-being constructs are reported in Table 2. Effect sizes were determined according to the guideline provided by Cohen (1988). Correlations reflect how the constructs for women relate to each other.

Table 2 shows that work engagement positively relates to psychological meaningfulness $(r=0.74$; large effect), life satisfaction ( $r=0.43$; medium effect), social support $(r=0.48$; medium effect) and supervisor support $(r=0.45$; medium effect). It negatively relates to work-family conflict ( $r=-0.15$; small effect). Psychological meaningfulness positively relates to life satisfaction ( $r=0.41$; medium effect), social support $(r=0.48$; medium effect) and supervisor support $(r=0.42$; medium effect). Work-family conflict negatively relates to supervisor support ( $r=-0.19$; small effect). Life satisfaction positively relates to social support $(r=0.38$; medium effect) as well as supervisor support $(r=0.32$; medium effect).

TABLE 2: Correlations coefficients for work engagement, psychological meaningfulness, work-family conflict, life satisfaction, social support and supervisor support.

\begin{tabular}{lccccc}
\hline Item & WE & PM & WFC & LS & SS \\
\hline Work engagement & - & - & - & - & - \\
Psychological meaningfulness & $0.74^{*}$ & - & - & - & - \\
Work-family conflict & $-0.15^{*}$ & -0.04 & - & - & - \\
Life satisfaction & $0.43^{*}$ & $0.41^{*}$ & -0.06 & - & - \\
Social support & $0.48^{*}$ & $0.48^{*}$ & -0.05 & $0.38^{*}$ & - \\
Supervisor support & $0.45^{*}$ & $0.42^{*}$ & $-0.19 *$ & $0.32^{*}$ & $0.54^{*}$ \\
\hline
\end{tabular}

WE, work engagement; PM, psychological meaningfulness; WFC, work-family conflict; LS, life satisfaction; SS, social support and supervisor support.

Practical significance: $r<0.10$ (small effect); $r<0.30$ (medium effect); $r<0.50$ (large effect). $*, p<0.05$
Supervisor support and social support positively relate to each other $(r=0.54$; large effect).

\section{Independent-sample $\boldsymbol{t}$-tests}

Independent-sample $t$-tests are reported for all the demographic variables on well-being of women in Tables 3-6.

Table 3 shows the results of the independent samples $t$-tests investigating the significance of the relationship between well-being constructs and marital status. It was found that women experience significant differences in levels of work engagement, psychological meaningfulness, work-family conflict and life satisfaction based on marital status. More specifically, married women experienced higher levels of work engagement, psychological meaningfulness, workfamily conflict, life satisfaction and social support compared to unmarried women. There is a small effect size for the difference between married and unmarried women for the specified variables.

Table 4 reports the results of the independent samples $t$-tests investigating the relationship between race and the different well-being variables in our study. Significant differences were found, based on race, in work engagement, workfamily conflict and life satisfaction. White women reported higher levels of work engagement, psychological meaningfulness, work-family conflict and life satisfaction than black women. The effect sizes of these differences ranged between 0.19 and 0.35 , which indicates a small effect.

Table 5 shows the results of the independent samples $t$-test examining the relationship between age and the measured well-being constructs. As can be seen, older women reported significantly higher levels of work engagement, psychological

TABLE 3: Independent $t$-tests of marital status on well-being of women.

\begin{tabular}{|c|c|c|c|c|c|c|c|}
\hline \multirow[t]{2}{*}{ Item } & \multicolumn{2}{|c|}{ Unmarried } & \multicolumn{2}{|c|}{ Married } & \multirow[t]{2}{*}{$t$} & \multirow[t]{2}{*}{$p$} & \multirow[t]{2}{*}{ Cohen's $d$} \\
\hline & Mean & SD & Mean & SD & & & \\
\hline Work engagement & 36.35 & 11.66 & 38.57 & 9.99 & -2.91 & $0.02 *$ & 0.20 \\
\hline Psychological meaningfulness & 23.59 & 5.36 & 24.55 & 4.29 & -2.24 & $0.00 *$ & 0.20 \\
\hline Work-family conflict & 12.39 & 5.15 & 13.85 & 5.45 & -4.06 & $0.00 * a$ & 0.28 \\
\hline Life satisfaction & 22.35 & 7.11 & 24.59 & 5.94 & -2.16 & $0.00 *$ & 0.34 \\
\hline Social support & 39.99 & 9.07 & 40.95 & 7.78 & -1.78 & $0.02 *$ & 0.11 \\
\hline Supervisor support & 33.84 & 11.77 & 34.08 & 11.10 & -1.48 & $0.81^{\mathrm{a}}$ & 0.02 \\
\hline
\end{tabular}

SD, standard deviation.

a, Equal variance is assumed.

$*, p<0.05$

TABLE 4: Independent $t$-tests of race on well-being of women.

\begin{tabular}{|c|c|c|c|c|c|c|c|}
\hline \multirow[t]{2}{*}{ Item } & \multicolumn{2}{|c|}{ Black } & \multicolumn{2}{|c|}{ White } & \multirow[t]{2}{*}{$t$} & \multirow[t]{2}{*}{$p$} & \multirow[t]{2}{*}{$d$} \\
\hline & Mean & SD & Mean & SD & & & \\
\hline Work engagement & 35.54 & 12.26 & 38.40 & 9.63 & -2.64 & $0.01 *$ & 0.26 \\
\hline Psychological meaningfulness & 23.50 & 5.586 & 24.54 & 4.16 & -1.83 & 0.07 & 0.21 \\
\hline Work-family conflict & 11.64 & 4.99 & 14.00 & 5.32 & -4.28 & $0.00 * * a$ & 0.46 \\
\hline Life satisfaction & 22.49 & 6.66 & 24.07 & 6.46 & -2.25 & $0.03 * a$ & 0.24 \\
\hline Social support & 40.01 & 9.11 & 41.14 & 7.79 & -1.15 & 0.25 & 0.13 \\
\hline Supervisor support & 32.69 & 12.09 & 34.71 & 11.08 & -1.52 & 0.13 & 0.17 \\
\hline
\end{tabular}

SD, standard deviation.

a, Equal variance is assumed.

$*, p<0.05 ; * *, p<0.01$ 
TABLE 5: Independent $t$-tests of age on well-being of women.

\begin{tabular}{|c|c|c|c|c|c|c|c|}
\hline \multirow[t]{2}{*}{ Item } & \multicolumn{2}{|c|}{$18-34$} & \multicolumn{2}{|c|}{$35-65$} & \multirow[t]{2}{*}{$t$} & \multirow[t]{2}{*}{$p$} & \multirow[t]{2}{*}{$d$} \\
\hline & Mean & SD & Mean & SD & & & \\
\hline Work engagement & 35.88 & 10.86 & 38.94 & 10.90 & -2.57 & $0.01 *$ & 0.28 \\
\hline Psychological meaningfulness & 23.40 & 5.19 & 24.71 & 4.46 & -3.19 & $0.00 * a$ & 0.27 \\
\hline Work-family conflict & 13.13 & 5.36 & 13.25 & 5.30 & -0.31 & 0.76 & 0.02 \\
\hline Life satisfaction & 23.10 & 6.96 & 23.81 & 6.32 & -1.83 & 0.07 & 0.11 \\
\hline Social support & 39.56 & 8.88 & 41.75 & 7.91 & -2.68 & $0.00 *$ & 0.26 \\
\hline Supervisor support & 34.35 & 11.15 & 33.73 & 11.73 & 0.74 & 0.46 & 0.05 \\
\hline
\end{tabular}

SD, standard deviation.

a, Equal variance is assumed.

$*, p<0.05$

TABLE 6: Independent $t$-tests of education on well-being of women.

\begin{tabular}{|c|c|c|c|c|c|c|c|}
\hline \multirow[t]{2}{*}{ Item } & \multicolumn{2}{|c|}{ Secondary } & \multicolumn{2}{|c|}{ Tertiary } & \multirow[t]{2}{*}{$t$} & \multirow[t]{2}{*}{$p$} & \multirow[t]{2}{*}{$d$} \\
\hline & Mean & SD & Mean & SD & & & \\
\hline Work engagement & 36.98 & 11.64 & 37.50 & 9.88 & -0.97 & 0.33 & 0.05 \\
\hline Psychological meaningfulness & 23.85 & 5.11 & 24.22 & 4.65 & -0.88 & 3.84 & 0.08 \\
\hline Work-family conflict & 12.93 & 5.49 & 13.68 & 5.09 & -2.04 & $0.04^{* a}$ & 0.14 \\
\hline Life satisfaction & 22.41 & 6.84 & 24.351 & 6.33 & -3.18 & $0.00 * a$ & 0.29 \\
\hline Social support & 40.34 & 8.97 & 40.30 & 7.62 & -0.41 & 0.68 & 0.00 \\
\hline Supervisor support & 33.80 & 11.66 & 33.45 & 10.98 & 0.08 & 0.93 & 0.03 \\
\hline
\end{tabular}

SD, standard deviation.

a, Equal variance is assumed.

$*, p<0.05$

meaningfulness and social support than younger women. The effect sizes based on Cohen's $d$ indicated small variances.

Table 6 shows the results of the independent samples $t$-tests analysing the relationship between education and the measured well-being constructs. Women with a tertiary qualification experience more work-family conflict and are more satisfied with life compared to women with only a senior certificate (Grade 12). There is a small effect size for the difference in women with and without a tertiary qualification for the specified variables.

\section{Multiple regression analyses}

We conducted hierarchical regression analyses to determine the percentage of variance explained by each of the demographic variables. Separate regression analyses were conducted for work engagement, psychological meaningfulness, work-family conflict, life satisfaction social support and supervisor support. In each analysis, the demographic variables were entered step by step (one in each step).

Table 7 shows the results of the regression analysis conducted for work engagement.

Table 7 shows that marital status explained $10 \%$ of the variance in work engagement. Further, race explained an additional $14 \%$ variance above that of marital status. Age and education did not add significantly to the percentage of variance explained.

Table 8 indicates that marital status explained $10 \%$ of the variance in psychological meaningfulness, while race added $8 \%$ variance of psychological meaningfulness. An additional variance of $9 \%$ in psychological meaningfulness was found
TABLE 7: Variances explained by demographic variables on work engagement.

\begin{tabular}{llcccc}
\hline Model & Variable & $\boldsymbol{R}$ & $\boldsymbol{R}^{\mathbf{2}}$ & $\boldsymbol{\Delta} \boldsymbol{R}^{\mathbf{2}}$ & $\boldsymbol{p}$ \\
\hline 1 & Marital status & 0.102 & 0.010 & 0.01 & $0.024^{*}$ \\
2 & Race & 0.156 & 0.024 & 0.014 & $0.009^{*}$ \\
3 & Age & 0.167 & 0.028 & 0.003 & 0.188 \\
4 & Education & 0.176 & 0.031 & 0.003 & 0.199 \\
\hline
\end{tabular}

Dependent: Work engagement.

1 , Marital status $(\beta=2.222) ; 2$, Marital status, race $(\beta=2.59) ; 3$, Marital status, race, age $(\beta=1.401) ; 4$, Marital status, race, age, education $(\beta=1.279)$.

$*, p<0.05$

TABLE 8: Variances explained by demographic variable on psychological meaningfulness.

\begin{tabular}{llcccc}
\hline Model & Variable & $\boldsymbol{R}$ & $\boldsymbol{R}^{\mathbf{2}}$ & $\boldsymbol{\Delta} \boldsymbol{R}^{\mathbf{2}}$ & $\boldsymbol{p}$ \\
\hline 1 & Marital status & 0.098 & 0.010 & 0.010 & $0.03^{*}$ \\
2 & Race & 0.131 & 0.017 & 0.008 & $0.05^{*}$ \\
3 & Age & 0.163 & 0.027 & 0.009 & $0.03^{*}$ \\
4 & Education & 0.173 & 0.030 & 0.003 & 0.19 \\
\hline
\end{tabular}

Dependent: Psychological meaningfulness.

1 , Marital status $(\beta=0.957) ; 2$, Marital status, race $(\beta=0.859) ; 3$, Marital status, race, age $(\beta=1.036) ; 4$, Marital status, race, age, education $(\beta=0.579)$.

$*, p<0.05$

because of age. Education did not add significantly to the amount of variance explained.

Table 9 indicates that marital status explained 19\% of the variance in work-family conflict. Race added an additional $25 \%$ of the variance in work-family conflict, while education added an additional 7\% variance therein. Age did not add significant variance to work-family conflict.

Table 10 shows that marital status explains $28 \%$ of variance in life satisfaction. Levels of education added a further $23 \%$ increase in the variance of life satisfaction.

Table 11 shows that age resulted in an $18 \%$ variance in social support. Marital status, race and education did not explain significant variance in social support. 
TABLE 9: Variances explained by demographic variable on work-family conflict.

\begin{tabular}{llcccc}
\hline Model & Variable & $\boldsymbol{R}$ & $\boldsymbol{R}^{\mathbf{2}}$ & $\boldsymbol{\Delta} \boldsymbol{R}^{\mathbf{2}}$ & $\boldsymbol{p}$ \\
\hline 1 & Marital status & 0.136 & 0.019 & 0.019 & $0.002^{*}$ \\
2 & Race & 0.210 & 0.044 & 0.025 & $0.000^{*}$ \\
3 & Age & 0.223 & 0.050 & 0.006 & 0.087 \\
4 & Education & 0.239 & 0.057 & 0.007 & $0.05^{*}$ \\
\hline
\end{tabular}

Dependent: Work-family conflict.

1 , Marital status $(\beta=1.458) ; 2$, Marital status, race $(\beta=1.718) ; 3$, Marital status, race, age $(\beta=-0.869) ; 4$, Marital status, race, age, education $(\beta=0.931)$.

$*, p<0.05$

TABLE 10: Variances explained by demographic variable on life satisfaction.

\begin{tabular}{llcccc}
\hline Model & Variable & $\boldsymbol{R}$ & $\boldsymbol{R}^{\mathbf{2}}$ & $\boldsymbol{\Delta} \boldsymbol{R}^{2}$ & $\boldsymbol{p}$ \\
\hline 1 & Marital status & 0.169 & 0.028 & 0.028 & $0.000^{*}$ \\
2 & Race & 0.185 & 0.034 & 0.006 & 0.088 \\
3 & Age & 0.186 & 0.034 & 0.000 & 0.690 \\
4 & Education & 0.240 & 0.058 & 0.023 & $0.001^{*}$ \\
\hline
\end{tabular}

Dependent: Life satisfaction.

1, Marital status ( $\beta=2.241) ; 2$, Marital status, race $(\beta=1.012) ; 3$, Marital status, race, age $(\beta=0.255) ; 4$, Marital status, race, age, education $(\beta=2.062)$.

$*, p<0.05$

TABLE 11: Variances explained by demographic variable on social support.

\begin{tabular}{llcccc}
\hline Model & Variable & $\boldsymbol{R}$ & $\boldsymbol{R}^{\mathbf{2}}$ & $\boldsymbol{\Delta} \boldsymbol{R}^{\mathbf{2}}$ & $\boldsymbol{p}$ \\
\hline 1 & Marital status & 0.057 & 0.003 & 0.003 & 0.221 \\
2 & Race & 0.094 & 0.009 & 0.006 & 0.104 \\
3 & Age & 0.133 & 0.018 & 0.009 & $0.042^{*}$ \\
4 & Education & 0.138 & 0.018 & 0.001 & 0.443 \\
\hline
\end{tabular}

Dependent: Social support.

1 , Marital status ( $\beta=0.961) ; 2$, Marital status, race $(\beta=1.285) ; 3$, Marital status, race, age $(\beta=1.733) ; 4$, Marital status, race, age, education $(\beta=0.611)$.

$*, p<0.05$

TABLE 12: Variances explained by demographic variable on supervisor support.

\begin{tabular}{llcccc}
\hline Model & Variable & $\boldsymbol{R}$ & $\boldsymbol{R}^{2}$ & $\boldsymbol{\Delta} \boldsymbol{R}^{2}$ & $\boldsymbol{p}$ \\
\hline 1 & Marital status & 0.010 & 0.000 & 0.000 & 0.822 \\
2 & Race & 0.068 & 0.005 & 0.004 & 0.148 \\
3 & Age & 0.091 & 0.008 & 0.004 & 0.182 \\
4 & Education & 0.092 & 0.009 & 0.000 & 0.786 \\
\hline
\end{tabular}

Dependent: Supervisor support.

1 , Marital status $(\beta=0.237) ; 2$, Marital status, race $(\beta=1.538) ; 3$, Marital status, race, age $(\beta=-1.528) ; 4$, Marital status, race, age, education $(\beta=-0.291)$.

$*, p<0.05$

The results reported in Table 12 indicated that none of the measured demographic variables explained significant amounts of variance in supervisor support.

\section{Discussion}

\section{Outline of the research}

The objective of this study was to examine the demographic differences in the experience of well-being of women in the workplace. Differences in the experiences of work engagement, psychological meaningfulness, life satisfaction, work-family conflict, social support and supervisor support of women were found based on race, age, marital status and education.

\section{Relationships between the well-being variables}

The results indicated that most of the well-being constructs were related. Work engagement, psychological meaningfulness, life satisfaction and support are positively related to each other. The findings of this study are in line with previous research on the relationship between work engagement, psychological meaningfulness and life satisfaction (cf. Van Zyl et al., 2012; Williamson \& Geldenhuys, 2014) as well as work engagement and support (cf. Barkhuizen \& Rothmann, 2006; Schaufeli \& Bakker, 2004). Work-family conflict is negatively related to work engagement, as is supervisor support. Previous research attests to the negative effect of work-family conflict on levels of engagement of employees (Opie \& Henn, 2013) and organisational support (Karatepe, 2009). The significant correlations found among the well-being constructs demonstrate that they are closely related. Even more significant is that the correlations are among work-related and non-work-related variables. This clearly signifies the importance of work, and experiences at work, in determining overall well-being - and vice versa. Work is an extremely important part of people's lives, and therefore employers cannot merely focus on work-related aspects when dealing with employees. Work cannot be compartmentalised and separated from employees' day-today lives, because work and private life are indeed intertwined. This is especially true in a modern work environment where, owing to technology, the boundaries between working time and private time are becoming increasingly blurred. Indeed, Currie and Eveline (2011) refer to 'work extensification and intensification' (Eveline, 2011, p. 539) to describe this blurring of lines between work and private life. In their study among academics with young children, one of the participants described the fact that technology allows him to work from anywhere, including home, as both a 'blessing and a curse' (Eveline, 2011, p. 542).

\section{Marital status}

The results indicate that married women experience higher levels of work engagement, psychological meaningfulness and life satisfaction compared to unmarried women. The findings of this study contradict those of Kong (2009), who reported that unmarried employees are more engaged. Takawira (2012) did find higher levels of vigour among married people. In the current study, marital status explained $10 \%$ of the variance in work engagement. It should be borne in mind that the current study only investigated women, whereas the other studies involved both genders. It seems plausible that being in a committed relationship enhances the well-being of participants, which spills over into positive appraisals of work. This can include enhanced work engagement and experiencing meaningfulness in work. Hakanen, Peeters and Perhoniemi's longitudinal study (2011) demonstrates the inter-relatedness of work and marriage: they found that job resources predicted work-to-family enrichment and the latter predicted work engagement (both over time). They also found that family-to-work enrichment had a positive influence on marital satisfaction (over time). These findings once again illustrate the enmeshed nature of work and family, and more specifically how work does indeed influence marital satisfaction indirectly. Combining these research findings, one comes to a tenable conclusion, namely that there may exist a reciprocal relationship 
between marital aspects such as quality of marital life, and work experiences such as work engagement.

In terms of life satisfaction, this study endorses the findings of numerous other studies that have shown that married people experience higher levels of life satisfaction (Botha \& Booysen, 2012; Filiz, 2014; Lee \& Lee, 2014; Ngoo et al., 2015; Stack \& Eshleman, 1998). Indeed, marital status explained a substantial $28 \%$ of the variance in life satisfaction. Increased life satisfaction, in turn, can influence work experiences positively. For instance, literature has shown job satisfaction to be an area-specific element of life satisfaction (refer to Bowling, Echlesman \& Wang, 2010; Veenhoven, 1991).

Married women also reported more work-family conflict. This study reports a $19 \%$ variance in work-family conflict because of marital status. Given that women bear the brunt of the household (taking care of children, husband and so forth), and based on the fact that women do more work in the home environment (OECD, 2011), it is expected that married women, especially those with families, will experience more work-family conflict.

\section{Race}

With regard to race, white women experienced significantly higher levels of work engagement, work-family conflict and life satisfaction compared to black women. Additionally, race explained a significant $14 \%$ of variance in work engagement, and a significant $25 \%$ of variance in work-tofamily conflict. This is in line with previous research findings regarding race and work engagement (Bell \& Barkhuizen, 2011) as well as with life satisfaction (Addai et al., 2014; Botha \& Booysen, 2012). Research by Fagley (2012), however, indicated no significant relationship between race and life satisfaction. It seems likely, as explained by Davis and $\mathrm{Wu}$ (2014), that racial identity determines the social group with which an individual compares himself. This, in turn, determines the individual's subjective perceptions of life satisfaction. Race may also act as a proxy for other factors that impact on life satisfaction, such as access to education and higher paying occupations.

There was no significant difference in the mean scores of psychological meaningfulness between black and white women, and this is in line with Hodson's (2002) findings in his study. In terms of work-family conflict, white women in this study experienced more conflict than black women, and this was a medium effect size. Previous research has been inconclusive in this regard. One study was found to be in line with the findings of this study (Childers \& Sage, 2004), while another study indicated that black employees experienced more conflict within their home-to-work life (cf. Steyl \& Koekemoer, 2011). The differences in findings may be samplespecific, and more research concerning the antecedents of work-family conflict is necessary. The experiences of black and white women with regard to employment, and subsequent work-family conflict, should be interpreted against the backdrop of South Africa's socio-political history.
During the era of apartheid, many black women had to leave their children in the care of grandparents while they themselves migrated to the cities where they could find employment. It stands to reason that these working mothers could focus on their work without having to balance it with childcare (of course migratory labour had many disadvantages - among them the emotional impact of being separated from one's children for extended periods of time but it is not the purpose of this discussion to dwell on these). As Russell (2003) puts it, migrant workers are 'geographically mobile and effectively single' (Russell, 2003, p. 171), and this makes them rather desirable employees. Implicit herein is the understanding that these 'effectively single' employees will not be distracted from their work by family demands. There are currently still many black women who are involved in migratory labour (cf. Phillips \& James, 2014). Although the extended family remains the dominant family structure among black South Africans, there is also a shift towards nuclear families (i.e. mother, father and children living together) (cf. Amoateng \& Heaton, 2015). Given this mixture of nuclear families, extended families and families affected by migratory labour, it is difficult to obtain a clear answer as to the experiences of work-family conflict among black people, hence the inconclusive research results.

\section{Age}

Women between the ages of 35 and 65 experienced higher levels of work engagement and psychological meaningfulness compared to women between the ages of 18 and 34. Research attests to the positive correlation between age and work engagement (Bezuidenhout \& Cilliers, 2011; Fong \& Ng, 2012; Mahboubi et al., 2014). With age comes greater maturity, and women may be better able to decide what job they should be doing. Older employees are also, by implication, further along in their career paths, so chances are good that they find themselves doing what they really want to do. It is plausible that this combination of factors can result in older women being more likely to find meaning in their work, and consequently also be more engaged in it. Other research found no such relationship (cf. Durksen \& Klassen, 2012; Takawira, 2012). It is assumed that older people may experience more meaning in work, as Chalofsky and Krishna (2009) allude to the idea of older people becoming more aware of their purpose in life. One way to interpret research findings is to refer to life stages and life cycle, as these are closely aligned to age. In this regard, Erik Erikson's eight stages of psycho-social development (described in Meyer \& Van Ede, 1990) present us with a theoretical context within which to explain our findings. According to this theory, the greatest challenge in early adulthood is to find a relationship to which to commit. In middle adulthood, the main challenge revolves around making a meaningful contribution in life, and in retirement the main challenge is to find satisfaction with life in general and the contributions you have made. The latter two phases of adulthood lend themselves to a greater search for meaning, which would also find expression in a search for meaning in terms of work. 
Interestingly, there was a significant difference in the experience of social support between the two age groups, with women aged 18-34 reporting higher levels of social support than women aged 35-65. Unfortunately, owing to unequal group sizes, we had to lapse the age categories into two categories, making it difficult to interpret the results regarding age. Notwithstanding this challenge, Erikson's theory may also contribute towards explaining our findings regarding age and social support. In the earlier phases of adulthood, individuals are more concerned with the establishment of meaningful relationships, whereas in later phases individuals are more concerned with their contributions to the world and having peace with their life. Older individuals may therefore be less concerned with support from others. Older employees may also be more confident and self-reliant, as they have built competency and skill over time. More research with larger samples is required to truly understand the relationship between perceptions of social support and age.

\section{Education}

The results showed that participants with some form of tertiary education experienced higher levels of life satisfaction and work-to-family conflict. With regard to life satisfaction, this finding is in line with literature (Daraei \& Mohajery, 2013). As indicted earlier, education is a portal to higher paying occupations and subsequent higher standards of living (cf. Schimmel, 2009). Higher incomes and socioeconomic class have in fact been positively linked with life satisfaction in previous studies (Addai et al., 2014; Botha \& Booysen, 2012; Jivray \& Nazroo, 2014). Indeed, education explained a significant $23 \%$ of variance in life satisfaction. Educated women are able to attract higher level jobs because of their qualification. This can result in women being more satisfied with their life because they might be able to afford a better lifestyle.

The finding that participants with tertiary education experienced higher levels of work-to-family conflict than those with a high school education is similar to the findings in a number of other studies (Childers \& Sage, 2014; Gaspar, 2013; Noor, 2003; Ozutku \& Altindis, 2013). As mentioned, Schieman and Glavin (2011) reported a curvilinear relationship between education and work-family conflict, with participants with higher (post school) and lower (less than high school) levels of education reporting higher levels of work-family conflict than those with a high school education. They proposed that participants with higher levels of education may experience 'stress of higher status' (Schieman \& Glavin, 2011, p. 1342), in other words, the demands placed on them by senior levels of work may cause increasing strain in terms of balancing work and family.

\section{Limitations and recommendations}

As this study worked with an existing database, it is possible that well-being constructs not included in our study may also be affected by demographic variables. Future studies can include variables such as job satisfaction, family-to-work conflict and burnout. The study was cross-sectional, and therefore no conclusions regarding cause and effect could be drawn. Owing to unequal sample sizes in terms of the demographic variables, we had to collapse each demographic variable into two categories. Future studies should aim to increase sample size, with large enough numbers of participants across all categories in a variable in order to maximise generalisability. This will enable the researchers to measure finer distinctions in demographic categories such as race, age, education and marital status.

\section{Practical implications}

The study provides ample support for the importance of demographic variables as determinants of well-being. Thus, from an organisational and managerial perspective, performance can be enhanced by acknowledging the different demographics of women that affect their work experiences. In this regard, it can be helpful to segment the workforce (e.g. in terms of relationship status, income, seniority level or education) to manage and support employees (cf. Nienaber et al., 2011). Further, it could be helpful in understanding the context within which women function or go about their work and personal life. In connection with this, employers should be mindful that demographic factors often serve as a proxy for lifecycle stages. For example, age can be an indicator of childbearing or menopause, and age of children can be an indicator of childcare - and flexitime needs.

Human resource $(\mathrm{HR})$ practitioners have a pivotal role in ensuring appropriate and supportive workplace practices for women (Abbott, 2012). More specifically, Abbott mentions aspects such as 'working hours, location of work, remuneration, and benefits' (Abbott, 2012, p. 21). Furthermore she also points out that the HR practitioner should ensure an appropriate fit between the employee and the organisation, and this includes lifestyle factors of the individual. Knowledge of the possible impact of demographic factors on employee well-being and hence organisational performance is therefore indispensable.

Kossek and Ozeki (1999) allude to two important factors that HR managers must pay attention to. Firstly, although many HR policies already allow for employees to utilise supportive practices (such as flexitime), employees often do not avail themselves of these opportunities. In their literature review, they found that a possible cause for this may be an unsupportive organisational culture. Indeed, an employee must 'experience' (Kossek \& Ozeki, 1999, p. 25) a policy as conducive before it will actually result in positive returns such as employee well-being and organisational commitment. Regarding work accommodation for pregnant women, Boninelli (2016) states that:

it is important that work accommodation not be viewed as unfortunate organisational costs needed to placate a special category of employees, but rather as an investment in a changed social climate and in female talent. (p. 10) 
This statement is in fact true for all supportive practices that an organisation makes available for women and certainly addresses the aspect of a non-supportive organisational culture.

Secondly, they advise that it is important to pin down the supportive practices considered most helpful and imperative for employees. They further urge researchers to utilise reliable scales to measure these. In the same way, HR practitioners should also utilise reliable scales to obtain this necessary information. More specific to our study, they should obtain data from different demographic groups in the organisation to ensure truly valuable results. Such scientifically valid results, combined with workforce segmentation, can assist employers in ensuring that best practices are applied that meet the needs of their employees while also serving the best interests of the organisation.

The practical implications of our research findings stretch further than merely addressing it through particular supportive practices and allowances in policies. It is essential that HR practitioners and HR managers ensure that policies are made available widely throughout the organisations, and to create awareness and tolerance thereof. Line managers should receive training so as to ensure that they understand the practical implications of the relevant policies (cf. Boninelli, 2016). This will prevent situations where line managers do not sanction, either directly or indirectly, their female employees' utilisation of allowed practices. HR practitioners should in fact champion the cause for the well-being of women (Abbott, 2012).

In line with our particular findings, HR practitioners should note the effect of age on well-being factors and link this to where an employee is in her life cycle. This will help towards establishing family-friendly workplace policies. With regard to relationship status, married women report higher levels of work-family conflict and may have a greater need for flexible work times, to name but one. Higher educational status can increase life satisfaction, and HR practitioners should consider practices such as opportunities for employees to improve their education. Concerning race, employees will benefit from diversity training. These are but a few ways in which HR practitioners can make practical use of our and other similar research findings.

\section{Conclusion}

This study demonstrates that demographic factors do influence well-being among working women. Being married correlated significantly with higher levels of life satisfaction, work-to-family conflict and work engagement. Marital status explained significant proportions of variance in work engagement, life satisfaction and work-to-family conflict. Being older correlated significantly with higher levels of work engagement. Age also explained significant percentages of variance in psychological meaningfulness, and social support at work. Higher education correlated positively with higher levels of life satisfaction and work-to-family conflict. Education also explained significant proportions of variance in life satisfaction and work-to-family conflict. In terms of race, white women experienced significantly higher levels of life satisfaction, work-to-family conflict and work engagement than black women. Race explained significant amounts of variance in psychological meaningfulness and work-to-family conflict. Understanding the impact of these factors can assist HR practitioners in effectively supporting and managing employees and designing policies and interventions - such as talent management - and retention strategies.

\section{Acknowledgements Competing interests}

The authors declare that they have no financial or personal relationships that may have inappropriately influenced them in writing this article.

\section{Authors' contributions}

M.G. and C.M.H. made an equal contribution on all sections (title, abstract, introduction, literature review, methodology and results, analyses and discussions) of this manuscript.

\section{References}

Abbott, P. (2012). Retention of women in the workplace - What HR practitioners can do. In A. Bosch (Ed.), South African board for people practices women's report 2012 (pp. 21-24). Parktown, South Africa: SABPP.

Addai, I., Opoku-Agyeman, C., \& Amanfu, S.K. (2014). Exploring predictors of subjective well-being in Ghana: A micro-level study. Journal of Happiness Studies, 15, 869-890. https://doi.org/10.1007/s10902-013-9454-7

Alcover, C.-M. (2012). Ageism in organizations? Perceived organizational support as a mediator of the relations between age and psychological contract breach. Revista Psicologia Organizacoes e Trabalho, 12, 299-313.

Allen, T.D., \& Finkelstein, L.M. (2014). Work-family conflict among members of fulltime dual-earner couples: An examination of family life stage, gender and age. Journal of Occupational Health Psychology, 19(3), 376-384. https://doi.org/10. 1037/a0036941

Amoateng, A.Y., \& Heaton, T.B. (2015). Changing race differences in family structure and household composition in South Africa. South African Review of Sociology, 46(4), 59-79. https://doi.org/10.1080/21528586.2015.1109476

Aselage, J., \& Eisenberger, R. (2003). Perceived organizational support and psychological contracts: A theoretical integration. Journal of Organizational Behavior, 24, 491-509. https://doi.org/10.1002/job.211

Bakker, A.B., Schaufeli, W.B., Leiter, M.P., \& Taris, T.W. (2008). Work engagement: An emerging concept in occupational health psychology. Work and Stress, 22(3) 187-200. https://doi.org/10.1080/02678370802393649

Balogun, A.G. (2014). Demographic variables predicting employee willingness to share tacit knowledge in service occupations. IFE PsychologIA, 22(2), 42-49.

Barkhuizen, E.N., \& Rothmann, S. (2006). Work engagement of academic staff in South African higher education institutions. Management Dynamics, 15(1), 38-48.

Bell, E., \& Barkhuizen, N. (2011). The relationship between barriers to change and the work engagement of employees in a South African property management company. South African Journal of Industrial Psychology, 37(1), 1-11. https://doi. org/10.4102/sajip.v37il.935

Bellavia, G.M., \& Frone, M.R. (2005). Work-family conflict. In J. Barling, E.K. Kelloway, \& M.R. Frone (Eds.), Handbook of work stress (pp. 113-147). Thousand Oaks, CA: Sage.

Bezuidenhout, A., \& Cilliers, F. (2011). Age, burnout, work engagement and sense of coherence in female academics at two South African universities. South African Journal of Labour Relations, 35(1), 61-80.

Boninelli, I. (2016). Career decisions for women considering pregnancy. In A. Bosch (Ed.), South African board for people practices women's report 2016 (pp. 7-13) Parktown, South Africa: SABPP.

Bosch, A. (2016). Pregnancy is here to stay - Or is it? In A. Bosch (Ed.), South African board for people practices women's report 2016 (pp. 3-6). Parktown, South Africa: SABPP.

Botha, F., \& Booysen, F. (2012). The relationship between marital status and life satisfaction among South African adults. Acta Academica, 45(2), 150-178. 
Boushey, H. (2008). "Opting out?" The effect of children on women's employment in the United States. Feminist Economics, 14(1), 1-36. https://doi.org/10.1080/ 13545700701716672

Bowling, N.A., Eschleman, K.J., \& Wang, Q. (2010). A meta-analytic examination of the relationship between job satisfaction and subjective wellbeing. The British relationship between job satisfaction and subjective wellbeing. The British
Psychological Society, 83, 915-934. https://doi.org/10.1348/096317909X478557

Braghin, C. (2009). Time-based constraints and work-to-family conflict among working mothers. Unpublished master's dissertation, University of Johannesburg, Johannesburg.

Casale, D. (2004). What has the feminisation of the labour market 'bought' women in South Africa? Trends in labour force participation, employment and earnings, 1995-2001. Working Paper 04/84. Cape Town, South Africa: Development Policy Research Unit.

Chalofsky, N., \& Krishna, V. (2009). Meaningfulness, commitment and engagement: The intersection of a deeper level of intrinsic motivation. Advances in Developing Human Resources, 11, 189-204.

Childers, C.D., \& Sage, J.A. (2004, August). Working women, work-family and familywork conflicts: A first look at differences in white women and women of colour. Paper presented at the American Sociological Association Conference, San Francisco, CA.

Cohen, J. (1988). Statistical power analysis for the behavioral sciences. (2nd edn.). Hillside, NJ: Erlbaum.

Cohen, J. (1992). A power primer. Psychological Bulletin, 112(1), 155-159. https://doi org/10.1037/0033-2909.112.1.155

Csikszentmihalyi, M. (1990). Flow: The psychology of optimal experience. New York: Harper \& Row.

Currie, J., \& Eveline, J. (2011). E-technology and work/life balance for academics with young children. Higher Education, 62, 533-550. https://doi.org/10.1007/s10734010-9404-9

Cusack, E.E., \& Numer, M. (2012). A phenomenological inquiry of social support in relation to health and wellbeing among rural queer female youth. The International Journal of Interdisciplinary Social Sciences, 6(4), 36-48. https://doi. org/10.18848/1833-1882/cgp/v06i04/52067

Daraei, M., \& Mohajery, A. (2013). The impact of socioeconomic status on life satisfaction. Social Indicators Research, 112(1), 69-81. https://doi.org/10.1007/ s11205-012-0040-x

Davis, L., \& Wu, S. (2014). Social comparisons and life satisfaction across racial and ethnic groups: The effects of status, information and solidarity. Social Indicators Research, 117, 849-869. https://doi.org/10.1007/s11205-013-0367-y

De Bruin, G.P., \& Henn, C.M. (2013). Uni-dimensionality of the Utrecht Work Engagement Scale 9 (UWES-9). Psychological Reports, 112(3), 1-12. https://doi. org/10.2466/01.03.PR0.112.3.788-799

De Klerk, M., Nel, J.A., \& Koekemoer, E. (2012). Positive side of the work-family interface: A theoretical review. Journal of Psychology in Africa, 22(4), 683-694.

De Lange, A.H., De Witte, H., \& Notelaers, G. (2008). Should I stay or should I go? Examining longitudinal relations among job resources and work engagement for stayers versus movers. Work \& Stress, 22(3), 201-223. https://doi.org/10.1080/ 02678370802390132

Demerouti, E., Bakker, A.B., Nachreiner, F., \& Schaufeli, W.B. (2000). A model of burnout and life satisfaction amongst nurses. Journal of Advanced Nursing, 32(2) 454-464. https://doi.org/10.1046/j.1365-2648.2000.01496.x

Diener, E., Emmons, A., Larsen, R.J., \& Griffin, S. (1985). The satisfaction with life scale. Journal of Personality Assessment, 49(1), 72-75. https://doi.org/10.1207/ s15327752jpa4901_13

Diener, E., Oishi, S., \& Lucas, R.E. (2003). Personality, culture, and subjective wellbeing: Emotional and cognitive evaluations of life. Annual Review of Psychology, $54,403-425$.

Douglas, S., \& Michaels, M. (2004). The mommy myth: The idealisation of motherhood and how it has undermined women. New York: Free Press.

Durksen, T.L., \& Klassen, R.M. (2012). Pre-service teachers' weekly commitment and engagement during a final training placement: A longitudinal mixed methods study. Educational \& Child Psychology, 29(4), 32-46.

Dwivedi, S., Kaushik, S., \& Luxmi. (2015). Organizational citizenship behaviour and demographic variables of employees in Indian Business Processing Outsourcing (BPO) sector. IUP Journal of Organizational Behaviour, 14(1), 39-57. https://doi. org/10.1002/job.2040

Eagle, B.W., Icenogle, M.L., Maes, J.D., \& Miles, E. (1998). The importance of employee demographic profiles for understanding experiences of work-family inter-role conflicts. The Journal of Social Psychology, 138(6), 690-709. https://doi. org/10.1080/00224549809603255

Erickson, J., Martinengo, G., \& Hill, E.J. (2010). Putting work and family experiences in context: Differences by family life stage. Human Relations, 63(7), 955-979. https://doi.org/10.1177/0018726709353138

Fagenson-Eland, E., \& Baugh, G. (2000). Career paths, networking, and mentoring. In D. Smith (Ed.), Women at work - Leadership for the next century (pp. 145-161). $\mathrm{NJ}$ : Prentice Hall.

Fagley, N.S. (2012). Appreciation uniquely predicts life satisfaction above demographics, the Big 5 personality factors, and gratitude. Personality and Individual Differences, 53, 59-63. https://doi.org/10.1016/j.paid.2012.02.019

Filiz, Z. (2014). An analysis of the levels of job satisfaction and life satisfaction of academic staff. Social Indicators Research, 116, 793-808. https://doi.org/10.1007/ s11205-013-0319-6
Fong, T.C., \& Ng, S. (2012). Measuring engagement at work: Validation of the Chinese version of the Utrecht Work Engagement Scale. International Journal of Behavioral Medicine, 19(3), 391-397.

Frankl, V.E. (1997). Man's search for ultimate meaning. New York: Plenum Press.

Gaspar, M.O. (2013). The modernisation process through the perceptions of work family in Spain and Great Britain. European Societies, 15(5), 707-728. https://doi. org/10.1080/14616696/2013.829241

Geldenhuys, M., Łaba, K., \& Venter, C.M. (2014). Meaningful work, work engagement and organisational commitment. South African Journal of Industrial Psychology, 40(1), 1-10. https://doi.org/10.4102/sajip.v40i1.1098

Greenhaus, J.H., \& Beutell, N.J. (1985). Sources of conflict between work and family roles. Academic of Management Review, 10, 76-88. https://doi.org/10.2307/ 258214, https://doi.org/10.5465/AMR.1985.4277352

Greenhaus, J.H., \& Parasuraman, S. (1999). Research on work, family and gender: Current status and future directions. In G.N. Powell (Ed.), Handbook of gender \& Current status and future directions. In G.N. Pow
work (pp. 391-415). Thousand Oaks, CA: Sage.

Hakanen, J.J., Peeters, M.C.W., \& Perhoniemi, R. (2011). Enrichment processes and gain spirals at work and at home: A 3-year cross-lagged panel study. Journal of Occupational and Organizational Psychology, 84(1), 8-30. https://doi.org/10. 1111/j.2044-8325.2010.02014.x

Haley, L., Mostert, K., \& Els, C. (2013). Burnout and work engagement for different age groups: Examining group-level differences and predictors. Journal of Psychology in Africa, 23(2), 283-296.

Henn, C.M. (2013). Measures of well-being. In C. Foxcroft \& G. Roodt (Eds.), Introduction to psychological assessment in the South African context (4th edn., pp. 171-184). Cape Town, South Africa: Oxford University Press.

Hodson, R. (2002). Demography or respect? Work group demography versus organizational dynamics as determinants of meaning and satisfaction at work. British Journal of Sociology, 53, 291-317. https://doi.org/10.1080/ 00071310220133359

Holvino, E. (2010). Intersections: The simultaneity of race, gender and class in organization studies. Gender, Work and Organisation, 17, 248-277. https://doi. org/10.1111/j.1468-0432.2008.00400.x

Huffman, A., Culbertson, S.S., Henning, J.B., \& Goh, A. (2013). Work-family conflict across the lifespan. Journal of Managerial Psychology, 28(7/8), 761-780. https:// doi.org/10.1108/JMP-07-2013-022

Jackson, L., \& Rothmann, S. (2005). Work-related well-being of educators in a district of the North-West Province. Perspectives in Education, 23(3), 107-122.

Jivray, S., \& Nazroo, J. (2014). Determinants of socioeconomic inequalities in subjective well-being in later life: A cross-country comparison in England and the USA Quality of Life Research, 23, 2545-2558. https://doi.org/10.1007/s11136-0140694-8

Kahn, W. (1990). Psychological conditions of personal engagement and disengagement at work. Academy of Management Journal, 33(4), 692-724. https://doi.org/10. 2307/256287

Karatepe, O.M. (2009). An investigation of the joint effects of organisational tenure and supervisor support on work-family conflict and turnover intentions. Journal of Hospitality and Tourism Management, 16, 73-81. https://doi.org/10.1375/ jhtm.16.1.73

Kong, Y. (2009). A study on the job engagement of company employees. International Journal of Psychological Services, 1(2), 65-68. https://doi.org/10.5539/ijps. v1n2p65

Kossek, E.E., \& Ozeki, C. (1999). Briding the work-family policy and productivity gap: A literature Review. Community, Work and Family, 2(1), 7-32. https://doi.org/10. 1080/13668809908414247

Kossek, E.E., Pichler, S., Bodner, T., \& Hammer, L.B. (2011). Work place social support and work-family conflict: A meta-analysis clarifying the influence of general and and work-family conflict: A meta-analysis clarifying the influence of general and
work-family specific supervisor and organisational support. Personnel Psychology, work-family specific supervisor and organisational support. Personne

Lambert, E.G., Hogan, N.L., Kelly, T.M., Kim, B., \& Garland, B. (2013). When domains spill over: The relationships of affective and continuance commitment with workfamily conflict among correctional staff. Criminal Justice Policy Review, 25(4), family conflict among correctional staff. Criminal Jus

Lee, E-K.O., \& Lee, J. (2013) Education, functional limitations, and life satisfaction among older adults in South Korea, Educational Gerontology, 39(7), 514-526. https://doi.org/10.1080/03601277.2012.701154

Liang, Y., \& Lu, P. (2014). Effect of occupational mobility and health status on life satisfaction of Chinese residents of different occupations: Logistic diagonal mobility models analysis of cross-sectional data on eight Chinese provinces. International Journal for Equity in Health, 13, 15.

Lips-Wiersma, M., \& Wright, S. (2012). Measuring the meaning of meaningful work: Developing and validation of the comprehensive meaningful work scale (CMWS) Group \& Organisation Management 37, 655-685. https://doi.org/10.1177/ 1059601112461578

Mahboubi, M., Ghahramani, F., Mohammadi, M., Amanis, N., Mousavi, S.H., Moradi, F., et al. (2014). Evaluation of work engagement and its determinants in Kermanshah hospitals staff in 2013. Global Journal of Health Sciences, 7, 170-176. https://doi.org/10.5539/gjhs.v7n2p170

Mandu, S., Buitendach, J., Kanengoni, H., \& Bobat, S. (2014). The prediction of turnover intention by means of employee engagement and demographic variables in a telecommunications organisation. Journal of Psychology in Africa, 24(2), 131-143.

Martinussen, M., Adolfsen, F., Lauritzen, C., \& Richardsen, A.M. (2012). Improving interprofessional collaboration in a community setting: Relationships with burnout, engagement and service quality. Journal of Interprofessional Care, 26, 219-225. https://doi.org/10.3109/13561820.2011.647125 
May, D., Gilson, R., \& Harter, L. (2004). The psychological conditions of meaningfulness, safety and availability and the engagement of the human spirit at work. Journal of Organisational Psychology, 77(1), 11-37. https://doi.org/10.1348/ 096317904322915892

Mazerolle, S.G., Bruening, J.E., \& Casa, D.J. (2008). Work-family conflict, Part I: Antecedents of work-family conflict in National Collegiate Athletic Association Division I-A certified athletic trainers. Journal of Athletic Training, 43(5), 505-512. https://doi.org/10.4085/1062-6050-43.5.505

McDowell, I. (2010). Measures of self-perceived well-being. Journal of Psychosomatic Research, 69, 69-79. https://doi.org/10.1016/j.jpsychores.2009.07.002

Meyer, W.F., \& Van Ede, D.M. (1990). Ontwikkelingsteorieë. In D.A. Louw (Ed.) Menslike Ontwikkeling (2de uitgawe, pp. 51-99). Pretoria, Suid Afrika: HAUM Tersiêr.

Mills, M.J., Culbertson, S.S., \& Fullagar, C.J. (2011). Conceptualizing and measuring engagement: An analysis of the Utrecht Work Engagement Scale. Journal of Happiness Studies, 13(3), 519-545. https://doi.org/10.1007/s10902-011-9277-3

Mostert, K. (2008). Time-based and strain-based work-family conflict in the South African police service: Examining the relationship with work characteristics and exhaustion. Acta Criminologica, 21(3), 1-18.

Netemeyer, R.G., Boles, J.S., \& McMurrian, R. (1996). Development and validation of work-family conflict scales. Journal of Applied Psychology, 81, 400-401. https:// doi.org/10.1037/0021-9010.81.4.400

Ngoo, Y.T., Tey, N.P., \& Tan, E.C. (2015). Determinants of life satisfaction in Asia. Social Indicators Research, 124, 141-156. https://doi.org/10.1007/s11205-014-0772-x

Nienaber, R., Bussin, M.H.R., \& Henn, C.M. (2011). The relationship between personality types and reward preferences. Acta Commercii, 1, 56-79.

Nomaguchi, K.M. (2011). Marital status, gender, and home-to-job conflict among employed parents. Journal of Family Issues, 33(3), 271-294. https://doi. org/10.1177/0192513X11415613

Noor, N.M. (2003). Work- and family-related variables, work-family conflict and women's well-being: Some observations. Community, Work \& Family, 6(3), 297-319. https://doi.org/1080/1366880032000143474

OECD (2011). Society at a glance 2011: OECD social indicators. OECD. Retrieved n.d., from https://www.oecd.org

Olivier, A.L., \& Rothmann, S. (2007). Antecedents of work engagement in a multinational oil company. South African Journal of Industrial Psychology, 33(3) 49-56. https://doi.org/10.4102/sajip.v33i3.396

O'Neil, D.A., Hopkins, M.M., \& Bilimoria, D. (2008). Women's career at the start of the 21st century: Patterns and paradoxes. Journal of Business Ethics, 80, 727-743. https://doi.org/10.1007/s10551-007-9465-6

Opie, T., \& Henn, S.M. (2013). Work-family conflict and work engagement among mothers: Conscientiousness and neuroticism as moderators. South African Journal of Industrial Psychology, 39(1), 1-12. https://doi.org/10.4102/sajip. v39i1.1082

Oyserman, D. (1993). The lens of personhood: Viewing the self and others in a multicultural society. Journal of Personality and Social Psychology, 65(5), 993-1009. https://doi.org/10.1037/0022-3514.65.5.993

Ozutku, H., \& Altindis, S. (2013). The relations between work intensity and workfamily conflict in collectivist culture: Evidence from Turkish health care professionals. Journal of Health Management, 15(3), 361-382. https://doi. org/10.1177/0972063413492049

Pallant, J. (2011). SPPS survival manual. (4th edn.). Buckingham: Open University Press.

Pavot, W., \& Diener, E. (1993). Review of the satisfaction with life scale. Psychological Assessment, 5, 164-172. https://doi.org/10.1037/1040-3590.5.2.164

Phillips, L., \& James, D. (2014). Labour, lodging and linkages: Migrant women's experience in South Africa. African Studies, 73(3), 410-431. https://doi.org/10.10 80/00020184.2014.962875

Pieterse, M., \& Mostert, K. (2005). Measuring the work-home interface: Validation of the survey work-home interaction - (SWING) instrument. Management Dynamics, 14(2), 2-15.

Rathi, N., \& Barath, M. (2013). Work-family conflict and job and family satisfaction: Moderating effect of social support among police personnel. Equality, Diversity and Inclusion: An International Journal, 32, 438-454. https://doi.org/10.1108/ and Inclusion: An

Rhoades, L., \& Eisenberger, R. (2002). Perceived organizational support: A review of the literature. Journal of Applied Psychology, 87, 698-714. https://doi.org/10. the literature. Journal of App

Rothmann, S., \& Rothmann, S. (2010). Factors associated with employee engagement in South Africa. South Africa Journal of Industrial Psychology, 36(2), 1-12. https:// doi.org/10.4102/sajip.v36i2.925
Russell, M. (2003). Are urban black families nuclear? A comparative study of black and white South African family norms. Social Dynamics, 29(2), 153-176. https://doi. org/10.1080/02533950308628679

Salinas-Jiménez, M., Artés, J., \& Salinas-Jiménez, J. (2011). Education as a positional good: A life satisfaction approach. Social Indicators Research, 103, 409-426. https://doi.org/10.1007/s11205-010-9709-1

Schafer, M.H., Mustillo, S.A., \& Ferraro, K.F. (2013). Age and the tenses of life satisfaction. Journals of Gerontology, Series B: Psychological Sciences and Social Sciences, 68(4), 571-579. https://doi.org/10.1093/geronb/gbt038

Schaufeli, W.B., \& Bakker, A.B. (2004). Job demands and job resources, and their relationship with burnout and engagement: A multi-sample study. Journal of Organisational Behaviour, 25(3), 293-315. https://doi.org/10.1002/job.248

Schaufeli, W.B., Salanova, M., González-Romá, V., \& Bakker, A.B. (2002). The measurement of engagement and burnout: $A$ two sample confirmatory factor analytic approach. Journal of Happiness Studies, 3, 71-92. https://doi.org/10. 1023/A:1015630930326

Schieman, S., \& Glavin, P. (2011). Education and work-family conflict: Explanations, contingencies and mental health consequences. Social Forces, 89(4), 1341-1362. https://doi.org/10.1093/sf/89.4.1341

Schimmel, J. (2009). Development as happiness: The subjective perception of happiness and UNDP's analysis of poverty, wealth and development. Journal of Happiness Studies, 10(1), 93-111. https://doi.org/10.1007/s10902-007-9063-4
Hol

Seligman, M.E.P. (2002). Authentic happiness. New York: Free Press.

Shanock, L.R., \& Eisenberger, R. (2006). When supervisors feel supported: The relationship with subordinates' perceived supervisor support, perceived organisational support and performance. Journal of Applied Psychology, 91, 689695. https://doi.org/10.1037/0021-9010.91.3.689

Sloan, M.M., Evenson-Newhouse, R.J., \& Thompson, A.B. (2013). Counting on coworkers: Race, social support and emotional experiences on the job. Socia Psychology Quarterly, 76, 343-372. https://doi.org/10.1177/0190272513504937

Sonnentag, S. (2003). Recovery, work engagement, and proactive behavior: A new look at the interface between non-work and work. Journal of Applied Psychology, 88(3), 518-528. https://doi.org/10.1037/0021-9010.88.3.518

Spreitzer, G. (1995). Psychological empowerment in the workplace: Dimensions, measurement and validation. Academy of Management Journal, 38(5), 14421465. https://doi.org/10.2307/256865

SPSS Inc. (2013). SPSS statistics for windows, version 22.00. Chicago, IL: SPSS Inc.

Stack, S., \& Eshleman, J.R. (1998). Marital status and happiness: A 17-nation study. Journal of Marriage and the Family, 60, 527-536. https://doi.org/10.2307/353867

Steger, M., Oishi, S., \& Kashdan, T. (2009). Meaning in life across the life span: Levels and correlates of meaning in life from emerging adulthood to older adulthood. The Journal of Positive Psychology, 4(1), 43-52. https://doi.org/10.1080/ 17439760802303127

Steyl, B., \& Koekemoer, E. (2011). Conflict between work and non-work roles of employees in the mining industry: Prevalence and differences between demographic groups. South African Journal of Human Resource Management 9(1), 1-14. https://doi.org/10.4102/sajhrm.v9i1.277

Takawira, N. (2012). Job embeddedness, work engagement and turnover intention of staff in a higher education institution. Unpublished master's dissertation, University of South Africa, Pretoria.

Thomas, L., \& Ganster, D. (1995). The impact of family supportive work variables on work-family conflict and strain: A control perspective. Journal of Applied Psychology, 80, 6-5. https://doi.org/10.1037/0021-9010.80.1.6

Triandis, H.C. (1989). The self and social behaviour in differing cultural contexts Psychological Review, 96, 506-520. https://doi.org/10.1037/0033-295X.96.3.506

Van Zyl, L., Deacon, E., \& Rothmann, S. (2010). Towards happiness: Experiences of work-role fit, meaningfulness and work engagement of industrial/organisational psychologists in South Africa. South African Journal of Industrial Psychology, 36(1), 10-20. https://doi.org/10.4102/sajip.v36i1.890

Veenhoven, R. (1991). Is happiness relative? Social Indicators Research, 24(1), 1-34. https://doi.org/10.1007/BF00292648

Voydanoff, P. (2004). The effects of work demand and resources on work-to-family conflict and facilitation. Journal of Marriage and Family, 66(2), 398-412. https:// doi.org/10.1111/j.1741-3737.2004.00028.x

Wegner, T. (2007). Applied business statistics: Method and excel-based applications. (2nd edn.). Cape Town, South Africa: Juta.

Williamson, J.C., \& Geldenhuys, M. (2014). Positive work experiences and life satisfaction: The moderating effect of gender. Journal of Psychology in Africa, 24 315-320.

Wolf, S. (2012). Meaning in life and why it matters. Princeton, NJ: Princeton University Press. 